\title{
Mode calculation and testing of a car body in
} white

\author{
Ying Yang ${ }^{\mathrm{a}, *}$, Guangyao Zhao ${ }^{\mathrm{a}}$, Dongbo $\mathrm{Ma}^{\mathrm{b}}$ and Xiaobin $\mathrm{Xu}^{\mathrm{a}}$ \\ ${ }^{a}$ School of Mechanical Engineering and Automation, Northeastern University, Shenyang, 110819, China \\ ${ }^{\mathrm{b}}$ Shenyang Aviation Vocational Technical College, Shenyang, 110043, China
}

Received 12 February 2010

Revised 23 June 2010

\begin{abstract}
The dynamic parameters of a car body in white (BIW) are important during a new car developing. Based on the finite element method, the model of a BIW is developed in which the welding points are treated specially as a new element type and the vibration modes of it are calculated. In modal testing, a fixed sine-sweeping exciter is used to conduct a single-point input force for the structure, whereas the output responses are picked up at different points to identify modes. The obtained modes are coincided both with the FE results and the practical testing.
\end{abstract}

Keywords: Vibration modes, finite element method, model testing

\section{Introduction}

In the designing process of a new car, it is a tedious but significant task to analyze and optimize the car body in white (BIW) thoroughly. From the view point of the smooth, comfort and NVH consideration, the dynamic characteristics of a BIW must meet the target requirements of dynamic properties besides sufficient strength, fatigue life and stiffness. That is, a BIW must possess good dynamic characteristics to control vibration and noise, so that the dynamic analysis of BIW should be achieved in early previous stage of design.

In order to obtain the vibration modes of a BIW, there are two main strategies of both calculated analysis and experimental testing in engineering. The former is mostly based on the finite element method (FEM), and the latter is based on the identification of structure responses excited by impulse or sine-sweep load. The FE based modes can represent the dynamic characteristics of a BIW, on the other hand, the tested results are necessary to verify for them.

Recently, mode analysis of BIW is well solved with the developed finite element analysis technology. Indeed, FEM, i.e. known as computer-aided design and analysis, has covered almost all aspects related to vehicle performance even for aerodynamics, crash simulation and occupant protection. Much popular commercial software provides powerful platform in the automobile designing $[1-3,14,19]$. The current issues include how to solve the practical problem in use at the design stage, how to improve the design quality, and how to shorten the developing period and save costs [5,11]. In the same situation, there are also many excellent instruments and analysis systems available for the vibration measurement and mode identification $[4,6]$.

In this paper, the vibration modes of an automobile BIW are investigated with both finite element method and experimental testing. The finite element model of the BIW is developed by particularly considering the welding points with the help of the software HyperMesh firstly. Then the modal analysis is achieved based on the FEM software of MSC.Nastran, and some important orders of the natural frequencies and corresponding vibration shapes of the BIW are obtained. In addition, experimental modal testing is conducted following the technique of single-point input exciting and multiple-point responses. Compared with the numerical mode results to that of the tested, they

${ }^{*}$ Corresponding author: Ying Yang, Tel.: +86 24 83691095; Fax: +86 24 83679731; E-mail: yangyang@ mail.neu.edu.cn. 
Table 1

Rigid cell description

\begin{tabular}{llc}
\hline $\begin{array}{l}\text { Name of } \\
\text { rigid cell }\end{array}$ & Description & $\begin{array}{c}\text { Restriction equation } \\
\text { numbers }(m)\end{array}$ \\
\hline PROD & Pull restriction along two nodes & 1 \\
PBAR & Rigidity connection between tow nodes & $1 \leqslant m \leqslant 6$ \\
RTRPLT & Rigidity connection among three nodes & $1 \leqslant m \leqslant 12$ \\
RBE1 & $\begin{array}{l}\text { Rigidity connection among random quantity nodes, } \\
\text { the freedom numbers both independency and correlat- }\end{array}$ & $m \geqslant 1$ \\
RBE2 & $\begin{array}{l}\text { ed are specified by user } \\
\text { Rigidity connection among random quantity nodes, } \\
\text { the independency freedom numbers are on appointed } \\
\text { reference point }\end{array}$ & $m \geqslant 1$ \\
\hline
\end{tabular}

Table 2

Material properties of the BIW

\begin{tabular}{lcccc}
\hline Body material & Welding material & Elastic modulus $\mathrm{N} / \mathrm{mm}^{2}$ & Poisson's ratio & Mass density $\mathrm{kg} / \mathrm{mm}^{3}$ \\
\hline 08AL & P-GMAW & $2.1 \mathrm{e} 5$ & 0.28 & $7.83 \mathrm{e}-12$ \\
\hline
\end{tabular}

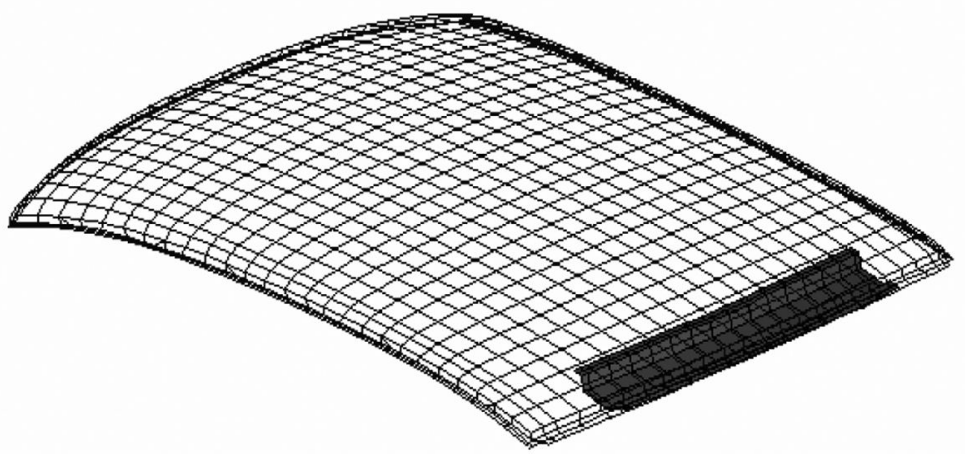

Fig. 1. Car roof model with crossbeam.

are coincided with each other fair well.

\section{FE based mode analysis and welding point description}

\subsection{Model description}

The whole structure of a BIW is simplified and modeled mathematically by choosing appropriate finite elements firstly. Especially, the BIW is made of so many welding parts that its model should be involved with suitable welding elements. It is critical to simulate the connections due to welding connection among different structure parts. Currently in the general FE software, some special kind of elements, such as pole cell, beam cell, board cell and rigid cell are boasted to be powerful to represent the welding points [12,14,17]. A rigid cell is often used to be a mechanical connector among different parts in assembled structures, which can be treated as a pole or a beam with infinite rigidity [15]. Here in the modal analysis of the BIW, the welding connections are modeled as rigid cells. The particular description of rigid cell is shown in Tables 1 and 2.

\subsection{Mesh generation}

The process of establishing a welding connection for BIW is described here, with an example of the car roof model connected with its crossbeam shown in Fig. 1. 
Table 3

The BIW model size

\begin{tabular}{lcc}
\hline Total element numbers & Weld points numbers & Freedom degrees of BIW \\
\hline 171697 & 4781 & 881421 \\
\hline
\end{tabular}

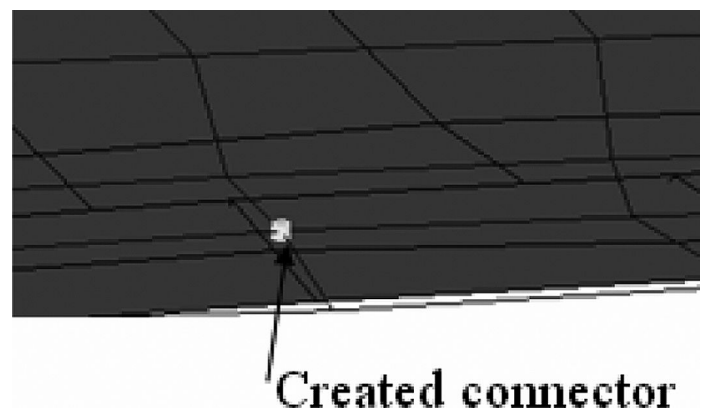

Fig. 2. Created connector.

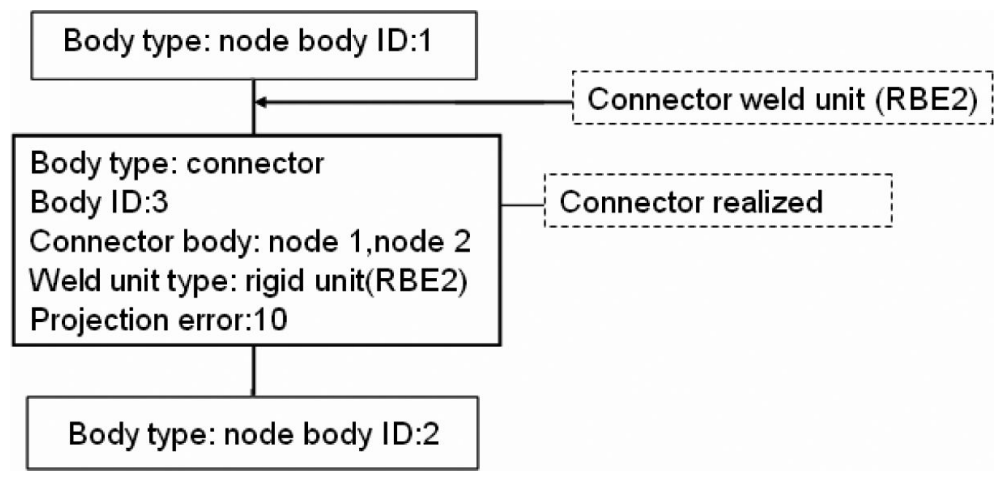

Fig. 3. The sketch map of realizing connector.

The process of using connector to establish welding is to create connectors. The connector welding management mode in HyperMesh is used to create and manage welding, which has six sub-interfaces. The connector used here is an entity but not a cell in finite element method. It can establish a joint relationship among different connected body. Among them, the connected body can be a part, a surface, a cell or a node. There are three main steps as stated as follows.

Step 1: Create connector

In this step, the connector's location, connect when, connect what, layers and connect rule are defined, shown in Fig. 2.

Step 2: Realize connector

The process of realizing connector is shown in Fig. 3.

Because the connection cell is a rigid cell, its material property is not needed. With a projection tolerance of 10 , the obtained connectors and new connect cells are shown in Fig. 4.

Step 3: Check the quality of the connector

The state of a connector can be classified as unconsummated connector, succeed realized connector and failed connector. They can also be displayed in green, yellow and red colors in Hypermesh. The successfully finished connections of the car roof and its crossbeam are shown in Fig. 5.

Step 4: Final meshing of BIW

After the welding points are all setup, the whole model of the BIW based on FEM is achieved, shown in Fig. 6 and Table 3. 


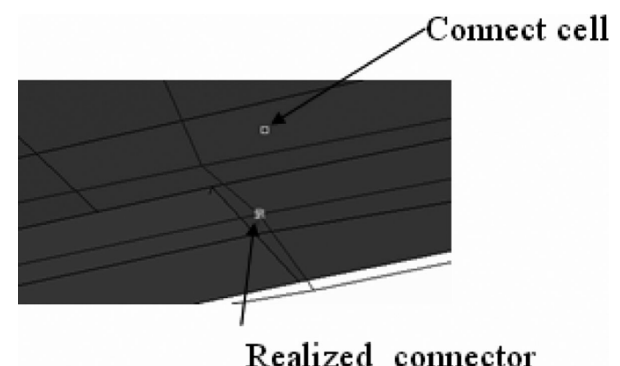

Fig. 4. Connector realized.

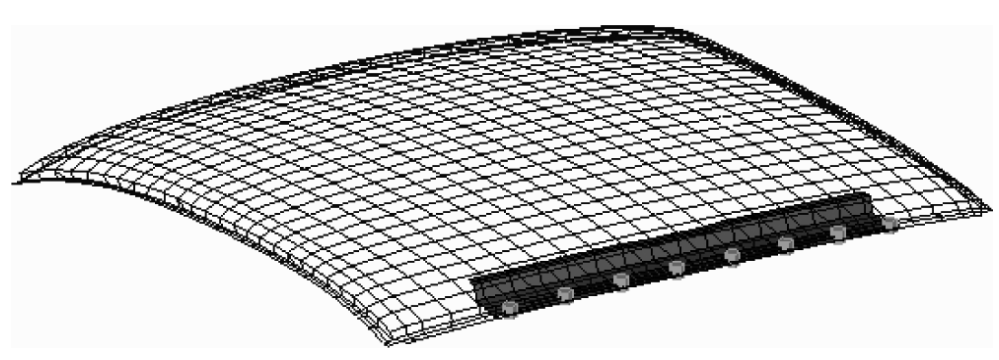

Fig. 5. Successful connection of car roof and crossbeam.

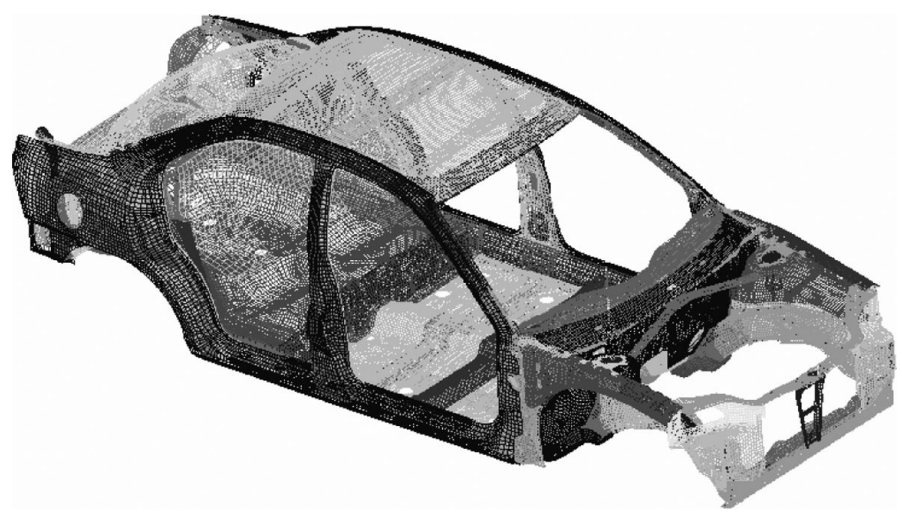

Fig. 6. Finite element model of BIW.

\subsection{Calculated modes of BIW}

With the above finite element model of the BIW, the modal analyses of it are carried out based on Nastran where Block Lanczos method is adopted. The calculated natural frequencies and vibration shapes are obtained, listed in Table 4. Some typical vibration shapes are shown in Fig. 7.

The material properties and the boundary conditions of the BIW will change the modes effectively, especially the welding connections. Take the roof panel as an example to illustrate the influence, in which the roof panel is modeled with single or double side constraints, as shown in Fig. 8.

For the first case of the model with single side constraints, the calculated modes from 1st to 4th order are listed in Table 5. The calculated modes from 1st to 4th order are listed in Table 6 for the roof panel modeled with double side constraints.

It can be seen that, from Tables 5 and 6, both the natural frequencies and vibration shapes of the panel are obviously changed with different boundary conditions. In addition, the vibration shapes of them do not change obviously with material property values. 
Table 4

Modal description of BIW with finite element model

\begin{tabular}{|c|c|c|}
\hline Mode orders & Natural frequency $(\mathrm{Hz})$ & Vibration shapes \\
\hline 1 & 28.13 & $\begin{array}{l}\text { Twist around the x-axis, large deformation in the front part (shown in } \\
\text { Fig. } 7 \text { (a)) }\end{array}$ \\
\hline 2 & 32.29 & $\begin{array}{l}\text { Twist around the x-axis, large deformation in the back part (shown in } \\
\text { Fig. } 7 \text { (b)) }\end{array}$ \\
\hline 3 & 41.21 & Bending vibration around the $x$-axis (shown in Fig. 7 (c)) \\
\hline 4 & 45.31 & Bending vibration around the $\mathrm{x}$-axis (shown in Fig. 7 (d)) \\
\hline 5 & 53.56 & $\begin{array}{l}\text { Bending vibration around the } x \text {-axis, local vibration in back window } \\
\text { ledge (shown in Fig. } 7 \text { (e)) }\end{array}$ \\
\hline 6 & 56.77 & $\begin{array}{l}\text { Vibration in the back part, more obvious in back window ledge (shown } \\
\text { in Fig. } 7 \text { (f)) }\end{array}$ \\
\hline 7 & 59.24 & $\begin{array}{l}\text { Twist around the x-axis, large vibration in the front and back part (shown } \\
\text { in Fig. } 7(\mathrm{~g}) \text { ) }\end{array}$ \\
\hline
\end{tabular}

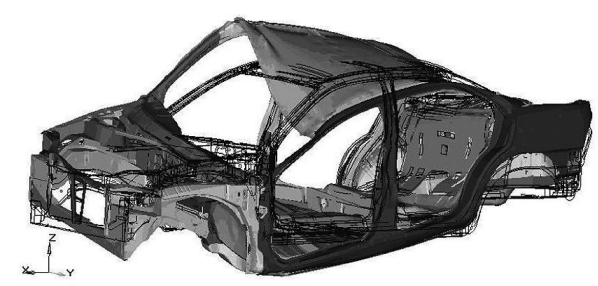

(a) The 1 st order vibration shapes

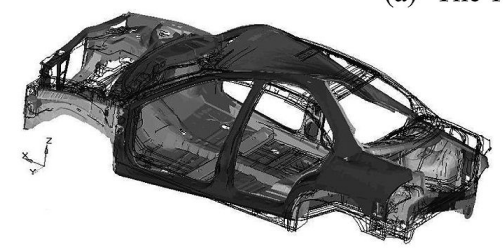

(b) The 2 nd order vibration shapes

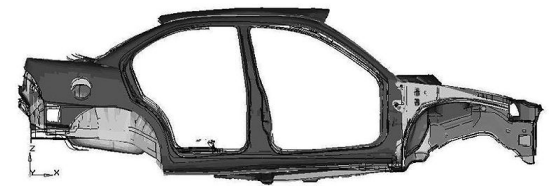

(d) The 4th order vibration shapes

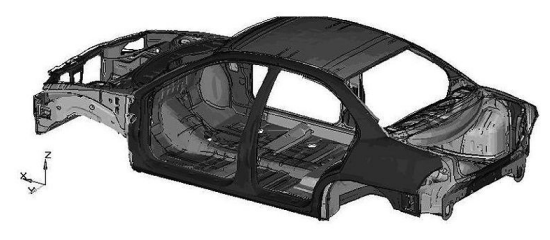

(f) The 6th order vibration shapes

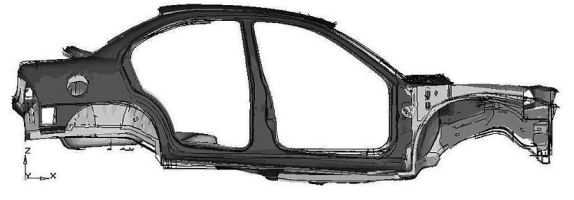

(c) The 3rd order vibration shapes

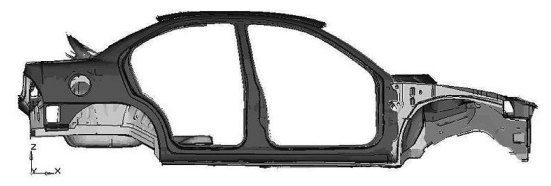

(e) The 5 th order vibration shapes

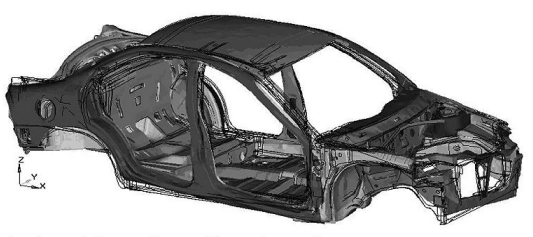

(g) The 7th order vibration shapes

Fig. 7. The 1 st -7 th order vibration shapes.

\section{Testing for modal analysis of BIW}

\subsection{Experimental setup for modal testing}

In the experimental setup, the BIW is suspended by some soft strings so that it can be regarded to be in a free-rigid state.

An exciter, together with the signal generator and a power amplifier, is used for the input excitation. Force sensors and acceleration sensors are used as transducers for measuring the input forces and responses of the structure. An 
Table 5

The structural different properties with single side constraint

\begin{tabular}{cccc}
\hline Orders & $\begin{array}{c}\text { Natural frequency under } \\
\text { original structure }(\mathrm{Hz})\end{array}$ & $\begin{array}{c}\text { Natural frequency under changed } \\
\text { structural property }(\mathrm{Hz})\end{array}$ & $\begin{array}{c}\text { The comparison of } \\
\text { vibration shapes }\end{array}$ \\
\hline Order1 & 6.961 & 6.551 & same \\
Order2 & 10.99 & 10.34 & same \\
Order3 & 48.88 & 46.98 & same \\
Order4 & 49.28 & 46.38 & same \\
\hline
\end{tabular}

Table 6

The calculated modes of a panel with two kinds of boundary conditions

\begin{tabular}{cccc}
\hline Orders & $\begin{array}{c}\text { Natural frequency of single } \\
\text { side constraint }(\mathrm{Hz})\end{array}$ & $\begin{array}{c}\text { Natural frequency of double } \\
\text { side constraints }(\mathrm{Hz})\end{array}$ & $\begin{array}{c}\text { Comparison of } \\
\text { vibration shapes }\end{array}$ \\
\hline Order1 & 6.961 & 109.7 & different \\
Order2 & 10.99 & 120.6 & different \\
Order3 & 48.88 & 130.7 & different \\
Order4 & 49.28 & 156.1 & different \\
\hline
\end{tabular}

Table 7

The modal testing results of BIW

\begin{tabular}{|c|c|c|}
\hline Orders & Natural frequency $(\mathrm{Hz})$ & Vibration shapes \\
\hline 1 & 27.50 & $\begin{array}{l}\text { Twist around the } \mathrm{x} \text {-axis, large deformation in the front part (shown in } \\
\text { Fig. } 11 \text { (a)) }\end{array}$ \\
\hline 2 & 31.12 & $\begin{array}{l}\text { Twist around the } \mathrm{x} \text {-axis, large deformation in the back part (shown in } \\
\text { Fig. } 11 \text { (b)) }\end{array}$ \\
\hline 3 & 39.24 & Bending vibration around the $\mathrm{x}$-axis, (shown in Fig. 11 (c)) \\
\hline 4 & 44.33 & Bending vibration around the x-axis, (shown in Fig. 11 (d)) \\
\hline 5 & 51.56 & $\begin{array}{l}\text { Bending vibration around the } \mathrm{x} \text {-axis, local vibration in back window } \\
\text { ledge }\end{array}$ \\
\hline 6 & 55.14 & Vibration in the back part more obvious in back window ledge \\
\hline 7 & 58.21 & Twist around the $\mathrm{x}$-axis large vibration in the front and back part \\
\hline
\end{tabular}

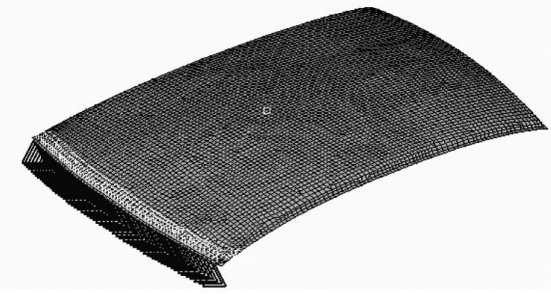

(a) The modeled panel with one side constraint

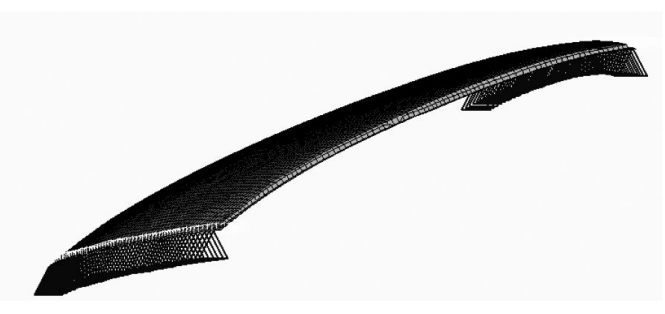

(b) The modeled panel with two side constraints

Fig. 8. The two different boundary conditions of a panel with single and double side constraints.

intelligent data acquisition system coming from LMS SCADAS III is used for recording the experimental process. LMS Test.lab provides the modal analysis. The flowchart of the modal testing of the BIW is shown in Fig. 9.

In the process of modal testing, the exciting point should not locate at the vibration shape nodes, and it can transmit the exciting force to the BIW easily. In addition, the rigidity near it should be great enough.

The responses of the BIW are measured at different structure points.

Before modal identification in LMS, the signals need to be filtered in order to reduce noises in both the force input and the acceleration responses.

\subsection{Algorithm of modal testing}

The algorithm of modal testing is based on the signal transforms and parameter identifications of the transfer function matrices in frequency domain, which the signals are measured experimentally. The modal parameters $\lambda_{r}$ 


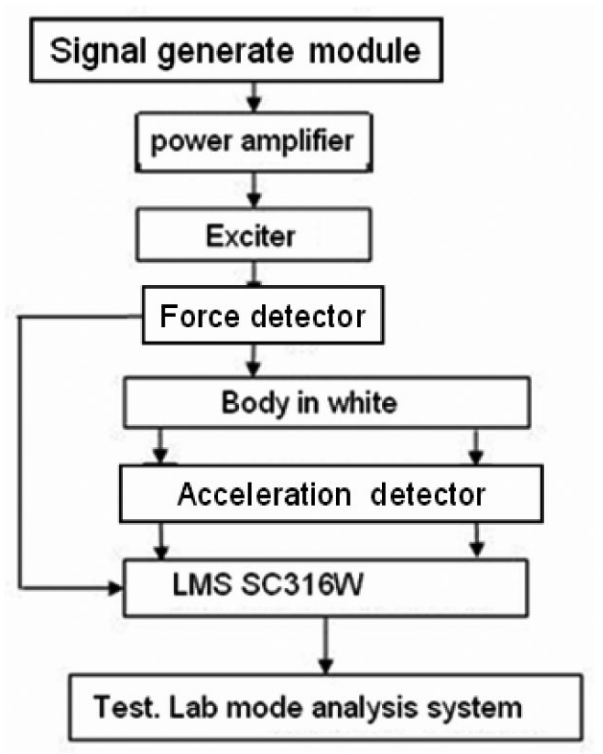

Fig. 9. The sketch map of mode testing system for BIW.

and $\{\Psi\}_{r}$ are estimated appropriately and the scale factor of vibration shapes are obtained in linear theory. The frequency response function matrix of structure is shown as follows.

$$
[H(j \omega)]=\sum_{r=1}^{N}\left(\frac{Q_{r}\{\Psi\}_{r}\{\Psi\}_{r}^{T}}{\left(j \omega-\lambda_{r}\right)}+\frac{Q_{r}^{*}\{\Psi\}_{r}^{* T}}{j \omega-\lambda_{r}^{*}}\right)
$$

Where $[H(j \omega)]$ is the frequency response function matrix; $\lambda_{r}$ is the eigen-value of the rth -order mode; $\{\Psi\}_{r}$ is the vibration shape function of the rth -order mode; $Q_{r}$ is the modal scale factor of the $\mathrm{rth}$-order mode. The variables of Eq. (1) whose upper right corner has a '*' are the corresponding conjugate complex.

Because of the limitation of testing, it is impossible to measure the full frequency response through experiment modal analysis. The numbers of mode will always be less than the numbers of response points, while the numbers of response points will always be less than the numbers of the degrees of freedom.

\subsection{Testing data processing and modes of BIW}

The testing data collecting and processing are handled synchronously. After a set of signals are obtained, the coherent function values of them are firstly checked and only those bigger than 0.8 are kept for calculating transfer functions next. An obtained frequency response function is shown in Fig. 10 (a), and its coherent function is shown in Fig. 10 (b). As shown in Fig. 10 (b), because the coherent function is almost equal to 1, this means that the input and output signals have a good linear relation.

For the BIW, the testing results of the natural frequencies and corresponding vibration shapes are shown in Table 7. Some vibration shapes are also shown in Fig. 11(a)-(d). The signal coherences and the obtained vibration shapes show that the modal results are reasonable.

\section{Comparison of calculating and testing modes}

Comparing the results obtained from FE calculated modes and the testing results of the BIW, it is shown that the natural frequencies and vibration shapes correspond to each other, just as shown in Table 8. But the calculated frequencies are a little bit greater than those of the tested. The reason for this difference concerns the structure damping assumption. For the natural frequency of a structure with damping, it is defined as follows. 


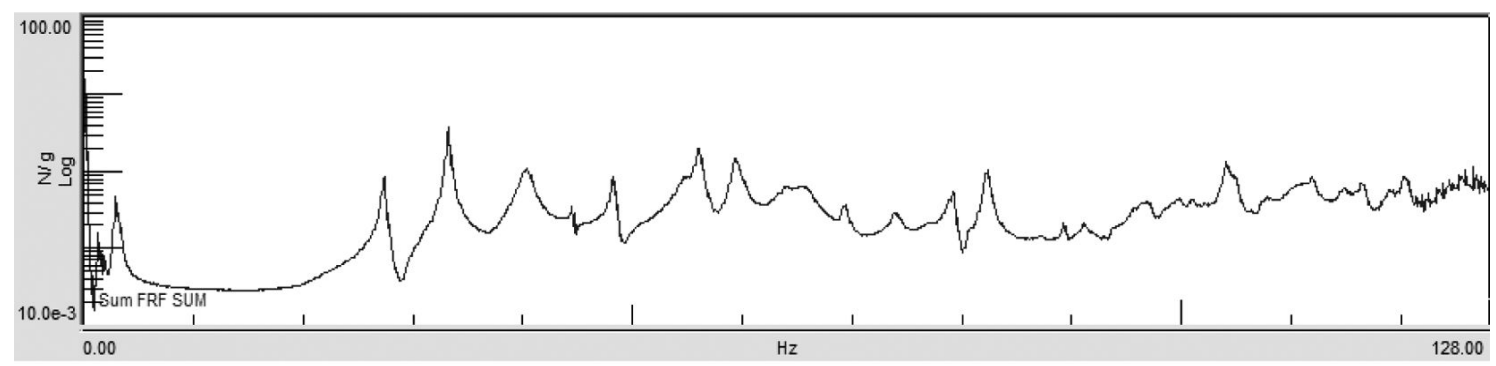

(a) Frequency response function

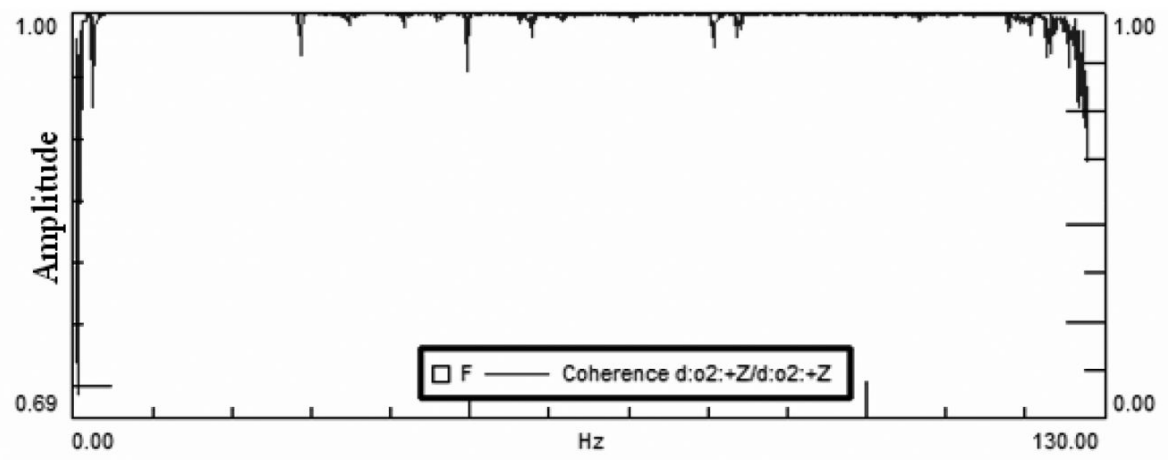

(b) Coherent function

Fig. 10. Frequency response function and coherent function obtained in modal testing.

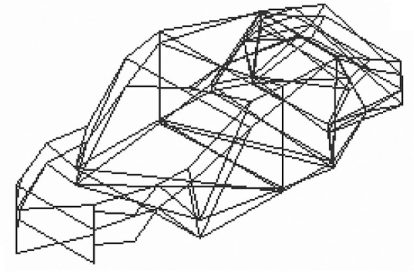

(a) The 1 st order vibration shapes

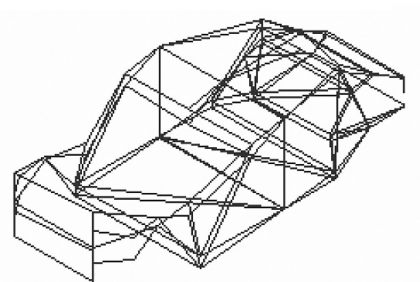

(c) The 3rd vibration shapes

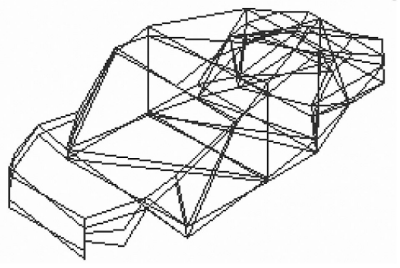

(b) The 2nd order vibration shapes

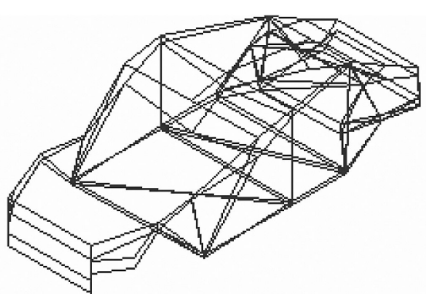

(d) The 4th order vibration shapes

Fig. 11. The 1st-4th order vibration shapes.

$$
\omega_{d}=\omega_{n} \sqrt{1-\zeta^{2}}
$$

Where $\omega_{d}$ is the natural frequency of the damping system; $\omega_{n}$ is the natural frequency of the corresponding un-damped system; $\zeta$ is the damping ratio and it is always a small parameter.

From the above Eq. (2), considering the calculated natural frequencies in Msc.Nastran under damping assumption, these results are acceptable.

For the obtained vibration shapes, take the 1st vibration shape of twist along x-direction as an example shown in Fig. 12, they are all similar one by one. 
Table 8

The natural frequency's comparison between theory modes and test modes

\begin{tabular}{lcc}
\hline Mode orders & $\begin{array}{c}\text { Theoretical natural } \\
\text { frequency }(\mathrm{Hz})\end{array}$ & $\begin{array}{c}\text { Tested natural frequency } \\
(\mathrm{Hz})\end{array}$ \\
\hline 1 & 28.13 & 27.50 \\
2 & 32.29 & 31.12 \\
3 & 41.21 & 39.24 \\
4 & 45.31 & 44.33 \\
5 & 53.56 & 51.56 \\
6 & 56.77 & 55.14 \\
7 & 59.24 & 58.21 \\
\hline
\end{tabular}

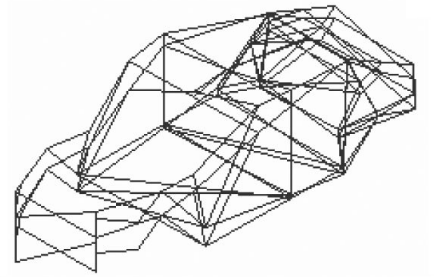

(a) The tested 1st order vibration shapes

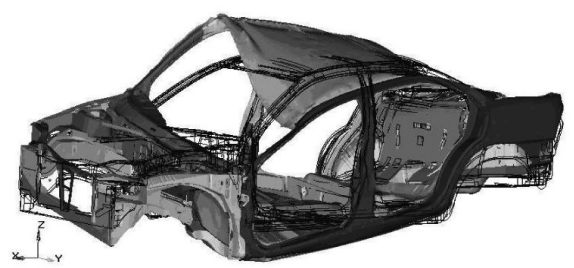

(b) The calculated 1 st order vibration shapes

Fig. 12. Comparison 1st order vibration shapes calculated with that tested.

Because the known limit of testing modal theory, the obtained testing modes are not as complete as the calculated modes based on FEM. The calculated modes can be used to determine the exciting and response picking locations for testing certainly. After all of the modes are verified by each other, they are important references in the designing of new automobile.

\section{Conclusions}

In this paper, the modal analysis of a BIW is achieved both with finite element method and experimental test. The finite element model is established with considering the special characteristics of welding points because the boundary conditions will change the modes sensitively.

Comparing with the calculated modes based on FEM to those of the tested of the BIW, it is shown that the natural frequencies and vibration shapes correspond to each other. These results will provide the basis for improving and optimizing the design of a car body.

\section{References}

[1] M. Brughmans, S. Goosense, T. Takei and V. Cibrario, Morphing technology applied to body modeling, Journal of Auto Vehicle Technique 57(7) (2003), 14-20.

[2] C.B. Chapman and M. Pinfold, The application of a knowledge based engineering approach to the rapid design and analysis of an automotive structure, Advances in Engineering Software 32(12) (2001), 903-912.

[3] S. Gao, Z. Deng and Y. Hu, A Study on the finite element modeling for spot-b welds of vehicle body, Automotive Engineering 30(9) (2008), $811-815$.

[4] G.H. James and T.G. Garne, The natural excitation technique for modal parameter extraction from operating structures, International journal of Analytical and Experimental Modal Analysis 10(4) (1995), 260-277.

[5] K. Kim and C. Kim, A study on the body attachment stiffness for the road noise, Journal of Mechanical Science and Technology 9(6) (2005), 1304-1312.

[6] H.M. Kim and D.A. Vanhorn, Free-decay time-domain modal identification for large space structures, Control and Dynamics 17(3) (1994), 513-519.

[7] Y. Liu, X. Peng and Y. Qin, FE simulation for concurrent design and manufacture of automotive sheet-metal parts, Journal of Materials Processing Technology 150(1-2) (2004), 145-150. 
[8] A. Ma, S. Chen and X. Li, Design sensitivity analysis of nonlinear response for large deflection forced vibrations of beams, Journal of Sound and Vibration 187(4) (1995), 683-693.

[9] R.H. MacNeal, Perspective on finite elements for shell analysis, Finite Elements in Analysis and Design 30(3) (1998), 175-186.

[10] R.H. MacNeal, C.T. Wilson, R.L. Harder and C.C. Hoff, The treatment of shell normals in finite element analysis, Finite Elements in Analysis and Design 30(3) (1998), 235-242.

[11] Y. Magoshi, H. Fujisawa and T. Sugiura, Simulation technology applied to vehicle development, Journal of Auto Vehicle Technique 57(3) (2003), 95-100.

[12] H.A. Nied, The finite element modeling of the resistance spot welding process, Welding Journal 63(4) (1984), $123-132$.

[13] B.K. Shahidi, W. Ho and B. Han, Steering column/instrument panel NVH analysis in full size pickup trucks using MSC/NASTRAN-Part 1, SAE Paper 962190 (1996), 364-366.

[14] K. Suzuki, CAE technologies and their applications to vehicle NVH design, Journal of Auto vehicle Technique 57(7) (2003), $21-27$.

[15] H. Takabatake and Y. Nagareda, A simplified analysis of elastic plates with edge beams, Computers and Structures 70(2) (1991), 129-139.

[16] P. Vanhonacker, Differential and difference sensitivities of natural frequencies and modal shapes of mechanical structures, AIAA 16(12) (1980), 1511-1514.

[17] S. Xu and X. Deng, An evaluation of simplified finite element models for spot-welded joints, Finite elements in analysis and design (2004) (40), 1175-1194.

[18] Z. Yu, Z. Lin and Y. Zhao, Evaluation of fracture limit in automotive aluminium alloy sheet forming, Materials and Design 28(1) (2007), 203-207.

[19] X. Zhang, Dynamic analysis and optimize design of NJ6400 white body structure, Journal of Mechanical Research and Application 15(3) (2002), 38-40. 

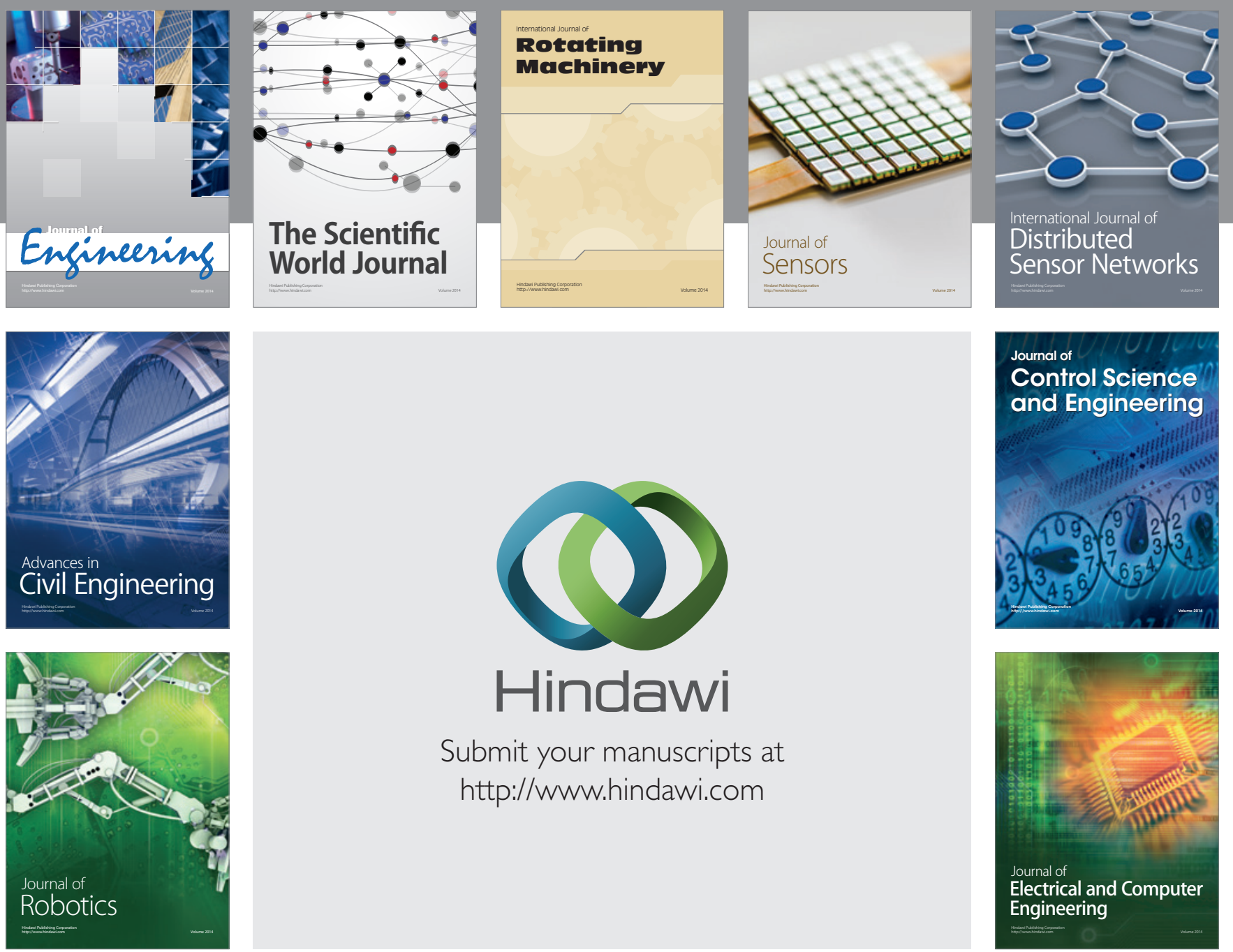

Submit your manuscripts at

http://www.hindawi.com
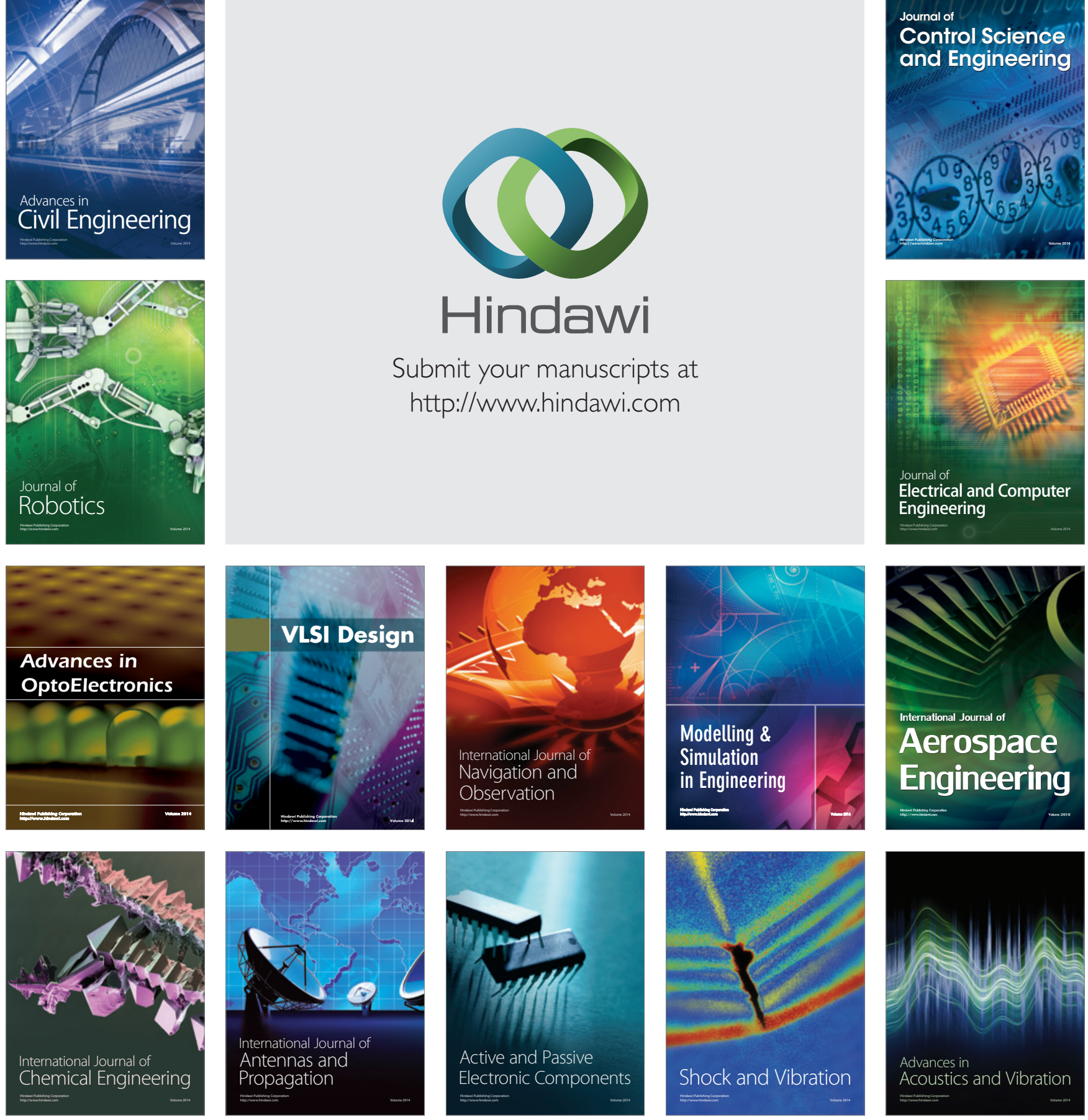